\title{
頭部3D-CTAにおける造影法 ーTDCから考える撮像時間を基準にした造影方法の検討一
}

2008年文受付

論文受理

2008年 4 月7昌

Code No. 251

\author{
寺沢和晶・八町 淳 \\ 長野赤十字病院中央放射線部
}

\section{緒 言}

近年，マルチスライスCT(multi-slice computed tomography：以下，MSCT)装置の急速な多列化に伴 い, three-dimensional CT angiography（以下，3DCTA)検査による血管系の診断は従来の血管造影検査 (angiography)に取って代わりつつある。これはCT検 査が非侵襲的であることと，特に検出器列が16列を 超える装置が登場したことによりほぼ全身の血管がカ バーできるようになったことによる影響が大きい。そ の結果，3D-CTAなど血管系のMSCT診断は普及の一 途をたどりはじめた。反面，MSCTは1998年に4列が
登場して以来，たつた 6 年間で64列まで発展し多様化 した。このため，CT装置は導入時期により施設間お よび施設内において大きな性能格差をもたらした。通 常，三次元再構成において体軸方向に高い連続性を得 るためには高い空間分解能が要求される。 それゆえ, 装置性能の多様化によって空間分解能を確保したうえ で撮像プロトコルを作成するには，MSCTの検出器列 数によって撮像時間が変化するといった不均衡が発生 する。また，造影剤の注入時間1,2) は撮像時間に左右 されるためCT装置の性能差はその造影法に大きく影 響を及ぼす。

\section{Contrast Enhancement Technique in Brain 3D-CTA Studies: Optimizing the Amount of Contrast Medium According to Scan Time Based on TDC}

\author{
Kazuaki Terasawa, and Atsushi Hatcho \\ Central Radiology Department, Nagano Red Cross Hospital \\ Received Feb. 8, 2008; Revision accepted April 7, 2008 ; Code No. 251
}

\section{Summary}

In three-dimensional CT angiography (3D-CTA), good reproducibility can be obtained by maintaining the maximum CT numbers (HU) at a specified level. However, the correlation between the scan time and the injection time showed that the maximum $\mathrm{CT}$ numbers increased and varied due to the additional contrast enhancement effect from recirculation of the injected contrast medium for longer injection times when the dose of iodinated contrast medium per unit time $(\mathrm{mgI} / \mathrm{s})$ was maintained at a specified level based on the time-density curve (TDC) of the phantom. The amount of contrast medium employed at our hospital has been optimized based on an iodinated contrast medium dose per unit time providing a contrast enhancement effect of $300 \mathrm{HU}$ in the middle cerebral artery. Using this standard, a TDC phantom was employed to obtain an iodinated contrast medium dose per unit time, permitting equivalent maximum CT values (used as standard values) to be obtained by changing the injection time. A contrast-enhancement technique that accounts for the variation in the scan time was evaluated. Strong correlations were observed between the scan time and the injection time $\left(\mathrm{R}^{2}=0.969\right)$ and between the injection time and the dose of iodinated contrast medium per unit body weight $\left(\mathrm{R}^{2}=0.994\right)$. We conclude that adjusting the dose of iodinated contrast medium per unit body weight per unit time according to the scan time permits optimization of the contrast-enhancement technique.

Key words: Brain 3D-CTA, contrast-enhancement technique, reproducibility, time-density curve (TDC), multi-slice computed tomography (MSCT) 
3D-CTAなど血管系の検査は最大CT值 $(\mathrm{HU})$ を一定 にすることが，再現性を得るためには必要不可欠であ る。しかし，再現性を確保するために単位時間におけ る単位体重毎ヨード量[以下，体重・時間毎ヨード量 $(\mathrm{mgI} / \mathrm{kg} / \mathrm{sec})]$ を一定にしても注入時間により最大CT 值が変化する。つまり，撮像時間の違いによりCT值 が変動することになる ${ }^{3)}$ 。したがって，撮像時間に応 じて最大CT值を一定にするための造影法が必要と考 えられた。 そこで今回われわれは, 血流評価用循環ファ ントムを用い, 注入時間が時間濃度曲線 (time-density curve : 以下，TDC $)^{4,5)}$ の最大CT值に与える影響および 3D-CTA検査における撮像時間を基準にした造影法を 検討したので報告する。

\section{1. 方 法}

\section{1-1 使用機器}

CT装置は東芝メディカルシステムズ社製Asteion 4 列MSCTシステム, Aquilion32列および64列MSCTシ ステムを使用した。また，自動注入器は根本杏林堂社 製のDual Shot-GXで，血流評価用循環ファントムは同 社製のTDCファントム6)を使用した(Fig. 1)。なお， 3Dワークステーション (3DWS) はZIOSOFT社製 ZIOSTATIONである.

\section{1-2 TDCファントムによる造影プロトコルの検討}

当施設において適正化して使用している体重・時間 毎ヨード量は, Asteion 4 列MSCTシステムにおいて 中大脳動脈部で300HUを得る体重・時間毎ヨード量 (1) $10 \mathrm{mgI} / \mathrm{kg} / \mathrm{sec}(45$ 秒注入)としている7). これを基準 とし， TDCファントムにより体重・時間毎ヨード量を 変化させ造影プロトコル (2) 35 秒注入と (3) 25 秒注入 において最大CT值が基準TDC (1) と同等になる体重・ 時間毎ヨード量を求めた。また，体重・時間毎ヨード 量を同一にした場合における注入時間の変化による影 響を観察するために $10 \mathrm{mgI} / \mathrm{kg} / \mathrm{sec} て ゙ 25$ 秒，35秒および 45秒注入のTDCを求めた。

\section{1-3 対象}

当施設においてAsteion 4 列MSCTシステム, Aquilion32列および64列MSCTシステムにより頭部 3D-CTAを実施した170名(男性81名，女性89名)であ る。なお，除外した対象はいない(Table 1).

\section{1-4 撮像方法}

撮像方法は，撮像時間が違い造影法を変化させたグ

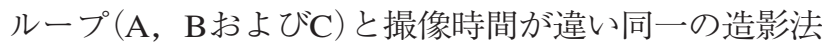
を施行したグループ( $\mathrm{B}^{\prime}$ と $\left.\mathrm{C}\right)$ のつの群とした。これ らにより，ファントム実験による妥当性，注入時間が

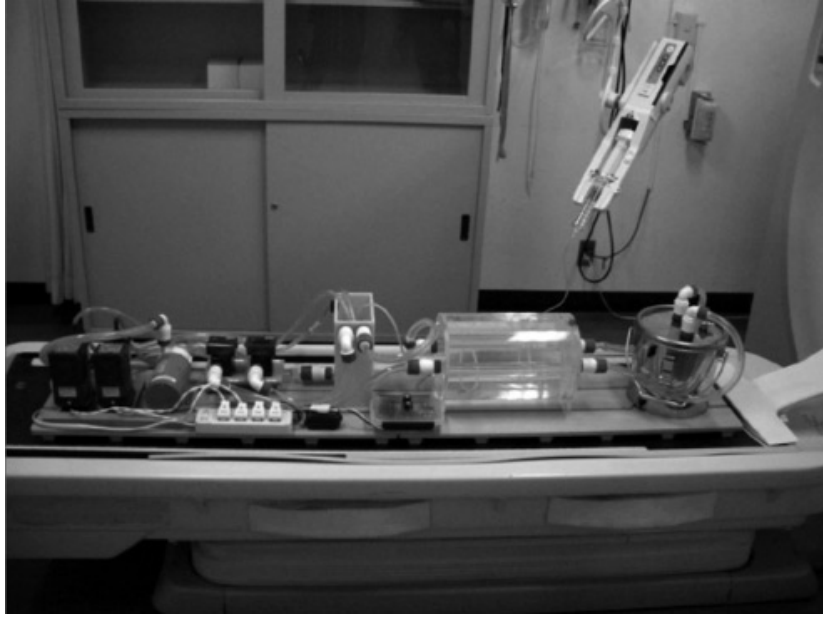

Fig. 1 TDC phantom and experimental setup.

Table 1 Number of subjects and contrast medium injection protocols for each group

\begin{tabular}{cccc}
\hline \hline group & $\mathrm{n}$ & protocol number & protocol $(\mathrm{mgl} / \mathrm{kg} / \mathrm{sec})$ \\
\hline A & 21 & 1 & 10 \\
B & 26 & $(2)$ & 11 \\
B $^{\prime}$ & 17 & $(3)$ & 12 \\
C & 106 & $(4)$ & 12 \\
\hline
\end{tabular}

* Scan time: Group A: approximately $25 \mathrm{sec}$, groups B and B': approximately $15 \mathrm{sec}$, group C: approximately $8 \mathrm{sec}$.

* CT systems used: Group A: Asteion 4-row MSCT scanner, groups B and B': Aquilion 32-row MSCT scanner, group C: Aquilion 64-row MSCT scanner. * Contrast medium injection time $=$ examination time $-15 \mathrm{sec}=$ (trigger time + time for voice messages and couch movement + scan time) -15 sec.

最大CT值に与える影響および撮像時間との関係を求 めた。

一群は撮像時間が25秒程度となるグループA，撮像 時間が 15 秒程度となるグループB，撮像時間が 8 秒程 度となるグループCで，造影プロトコルは2-1よりグ ループAはプロトコル (1), グループBはプロトコル (2)，グループCはプロトコル (3) を使用した。二群はグ ループBにおいてプロトコル (3)を使用したグループB' とCである。

撮像はボーラストラッキング法にてタイミングを捉 えた。また，インジェク夕同期を使用し，撮像が終了

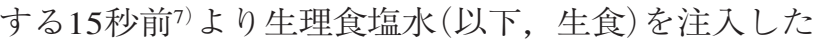
(Fig. 2).

\section{1-5 評価部位および評価方法}

各グループにおける中大脳動脈M1領域 (以下, MCA)のCT值と最終スライスにおける前大脳動脈(以 下，ACA）のCT值を測定し比較した。また，得られ た結果よりCT值低下率7)*を比較した。撮像範囲は, 


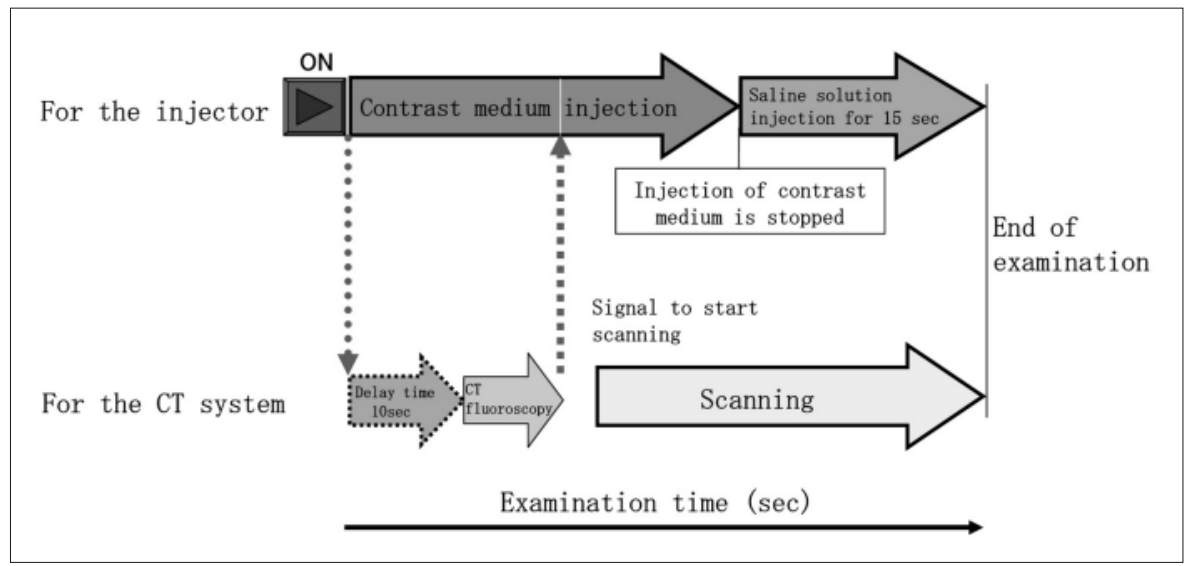

Fig. 2 Flowchart of 3D-CTA study using SureStart and the injector synchronization scan system.
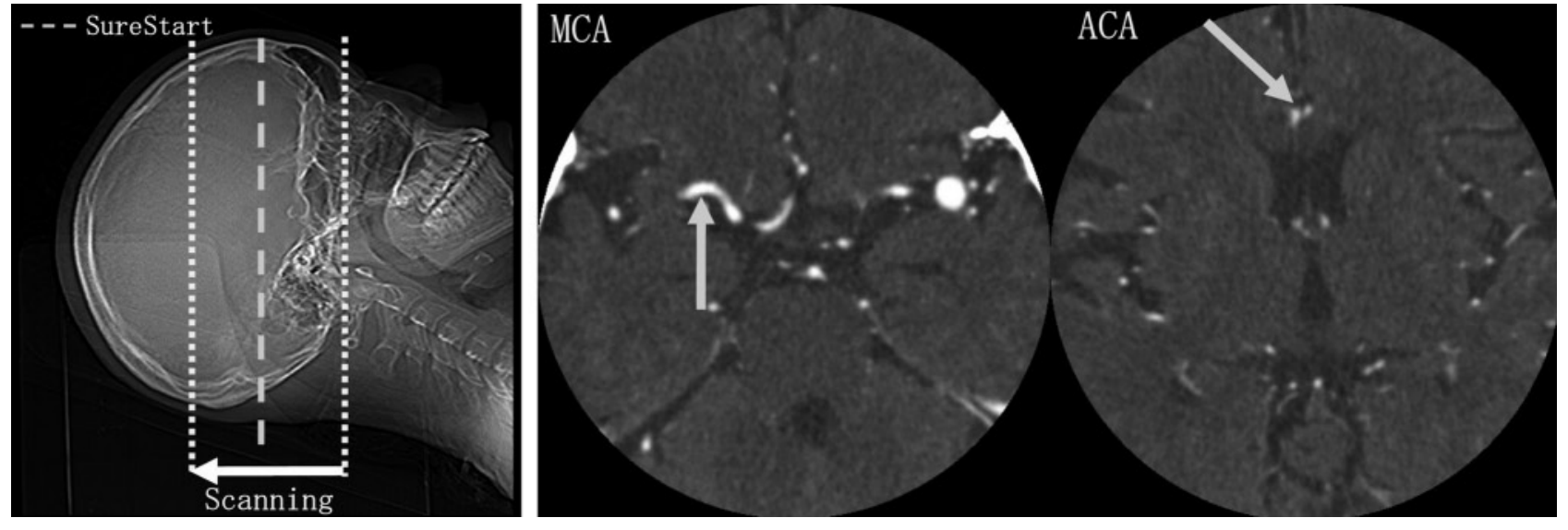

Fig. 3 (a) Scan range, (b) Anatomical regions to be evaluated.

Fig. 3 (a)に示す. 評価部位は, Fig. $3($ b) に示す.

*CT值低下率：生食後押し時間がACAの造影効果に 与える影響を観察するための值である。通常，血管径 の変化に伴いパーシャルボリュームなどによってCT 值に違いがあるため, MCAとACAのCT值を単純に比 較することはできない.そこで, MCAとACAのCT值 比の平均值から上昇したグループ(生食後押し時間： 5，10，15，20秒)において，ACAの血中濃度の低下 が起こったとして評価した值である。15秒までは $\mathrm{ACA}$ への影響はなかったことから，生食は撮像終了 の15秒前から注入することで造影剤の低減および適正 化が可能になる。このときのCT值低下率は平均で約 $25 \%$ であり，当施設の検討ではバラツキを考慮して30 \%程度までであれば臨床上，ほぼ影響はないとしてい る.

$\mathrm{CT}$ 值低下率 $(\%)=(\mathrm{MCA}-\mathrm{ACA}) / \mathrm{MCA} \times 100$

\section{2. 結 果}

2-1 TDCファントムによる造影プロトコル

TDCファントムにより, (2) $11 \mathrm{mgI} / \mathrm{kg} / \mathrm{sec}$ (35秒注 入), (3) $12 \mathrm{mgI} / \mathrm{kg} / \mathrm{sec}$ ( 25 秒注入)の造影プロトコルで 基準TDC (1) $10 \mathrm{mgI} / \mathrm{kg} / \mathrm{sec}$ (45秒注入) とほぼ同一の最 大CT值が得られた(Fig. 4). また，体重・時間毎ヨー ド量を同一にした場合において注入時間を変化させる と TDCの最大CT值は撮像時間の延長により上昇した (Fig. 5).これらのなかで，TDCは急激な上昇を呈し た後，緩やかに上昇しピークとなる 2 段階の形成過程 を示した。

2-2 撮像時間が違い造影法を変化させた一群(グ ループA, BおよびC)の造影効果

Table 2に一群における被検者データの平均值と標準

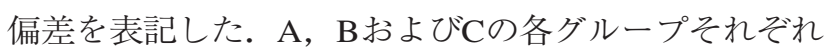
の CT值を比較すると, $\mathrm{MCA}$ はグループ A 


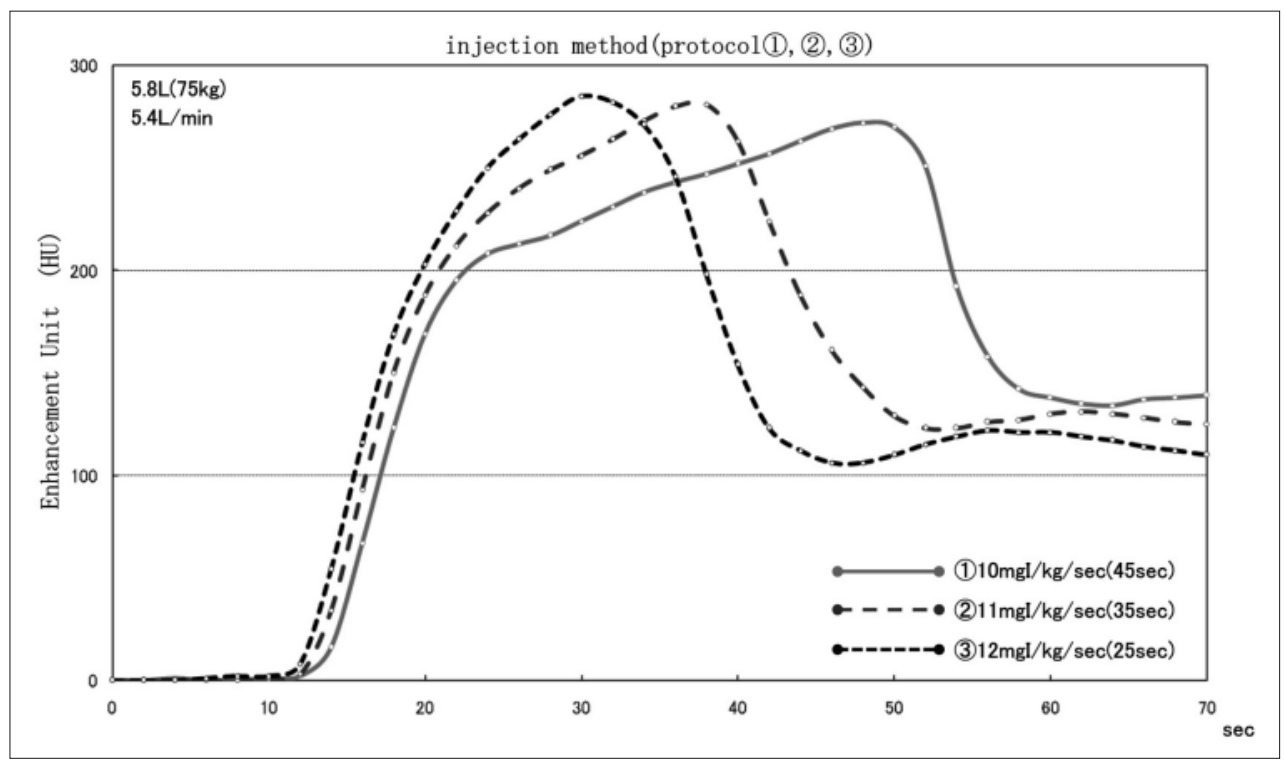

Fig. 4 Relationship between the injection time and maximum CT numbers when the dose of iodinated contrast medium per unit body weight per unit time $(\mathrm{mgl} / \mathrm{kg} / \mathrm{sec})$ was varied.

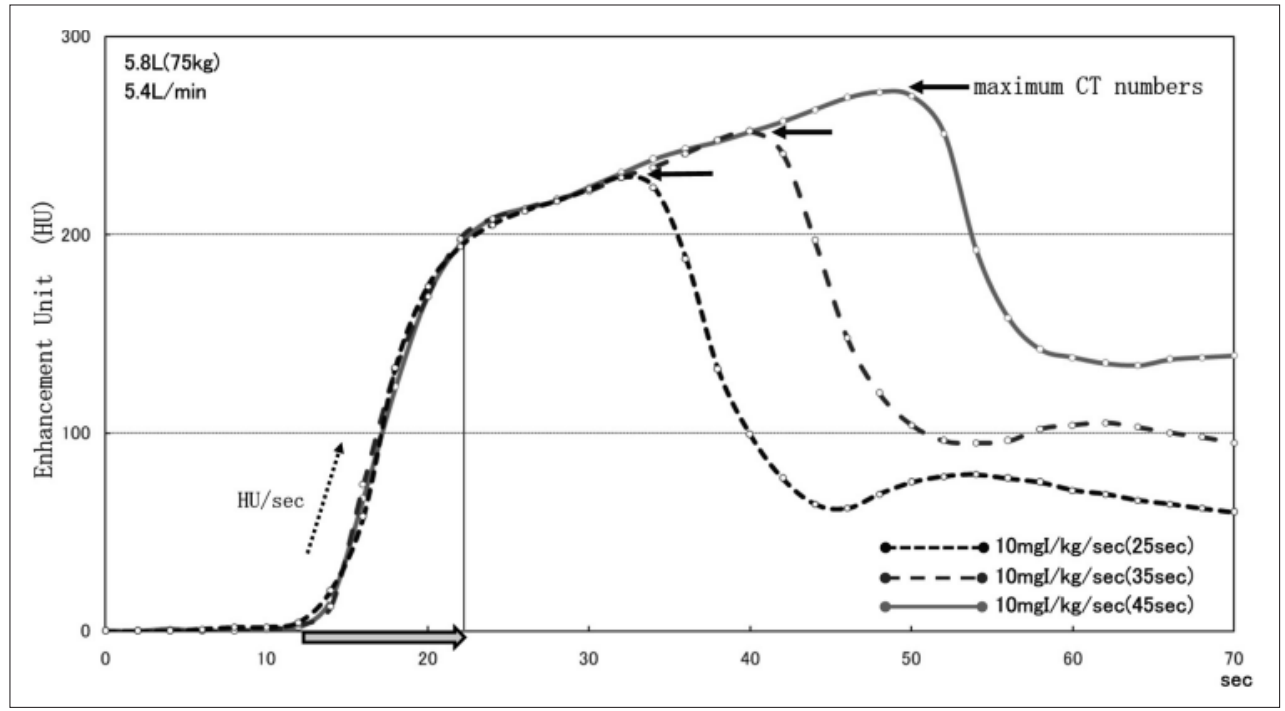

Fig. 5 TDCs in which recirculation of the injected contrast medium was added (relationship between injection time and maximum CT numbers).

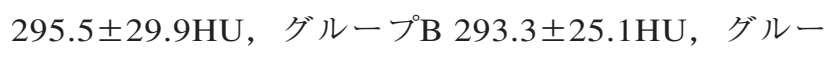
プC $297.5 \pm 29.7 \mathrm{HU}$ とな，ACAはグループA

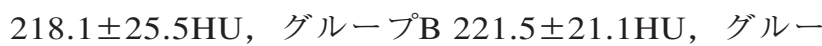
プC 226.4土28.1HUであった。各グループのMCA， ACAのCT值に有意な差は認められなかった。ただ

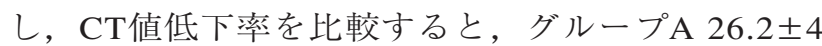

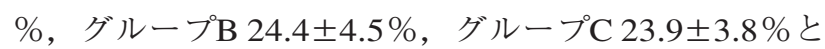
なり，グループ $\mathrm{A}$ とに有意差 $(\mathrm{P}<0.05)$ が認められた (Fig. 6). また，トリガータイミングを比較すると，

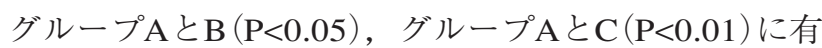
意差が認められた。なお， Table 3に一群における性別 の平均值と標準偏差を表記した。グループBとCにお
いて体重による性差があったがMCAのCT值とCT值低 下率に有意な差は認められなかった。

2-3 撮像時間が違い同一の造影法を施行した二群 (グループB'とC)の造影効果

Table4にプロトコルを同一にした二群における被検者 データの平均值と標準偏差を表記した。グループCに対

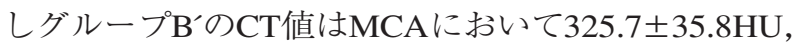
ACAにおいて246.4 228.1HUとなり MCAとACAのCT 值が有意 $(\mathrm{P}<0.01)$ に上昇した。しかし，CT值低下率 は，24.3土3.7\%であり有意な差は認められなかった (Fig. 7). 
Table 2 Mean and standard deviation of all data sets of the first groups (groups A, B, and C)

\begin{tabular}{ccccccccc}
\hline \hline group & $\begin{array}{c}\text { protocol } \\
(\mathrm{mgl} / \mathrm{kg} / \mathrm{sec})\end{array}$ & $\mathrm{n}$ & $\begin{array}{c}\text { body } \\
\text { weight } \\
(\mathrm{kg})\end{array}$ & $\begin{array}{c}\text { age } \\
(\mathrm{y})\end{array}$ & $\begin{array}{c}\text { trigger } \\
\text { time } \\
(\mathrm{sec})\end{array}$ & $\begin{array}{c}\text { CT number } \\
\text { MCA } \\
(\mathrm{HU})\end{array}$ & $\begin{array}{c}\text { CT number } \\
\text { ACA } \\
(\mathrm{HU})\end{array}$ & $\begin{array}{c}\text { CT number } \\
\text { reduction rate } \\
(\%)\end{array}$ \\
\hline $\mathrm{A}$ & 10 & 21 & $57.3 \pm 9.4$ & $62.9 \pm 9.6$ & $21.5 \pm 3 \star \star *$ & $295.5 \pm 29.9$ & $218.1 \pm 25.5$ & $26.2 \pm 4 \star$ \\
$\mathrm{B}$ & 11 & 26 & $61.6 \pm 10.9$ & $58.3 \pm 16.8$ & $19.5 \pm 2.3$ & $293.3 \pm 25.1$ & $221.5 \pm 21.1$ & $24.4 \pm 4.5$ \\
$\mathrm{C}$ & 12 & 106 & $56.8 \pm 10.8$ & $64.4 \pm 12$ & $19.8 \pm 2.9$ & $297.5 \pm 29.7$ & $226.4 \pm 28.1$ & $23.9 \pm 3.8$ \\
\hline
\end{tabular}

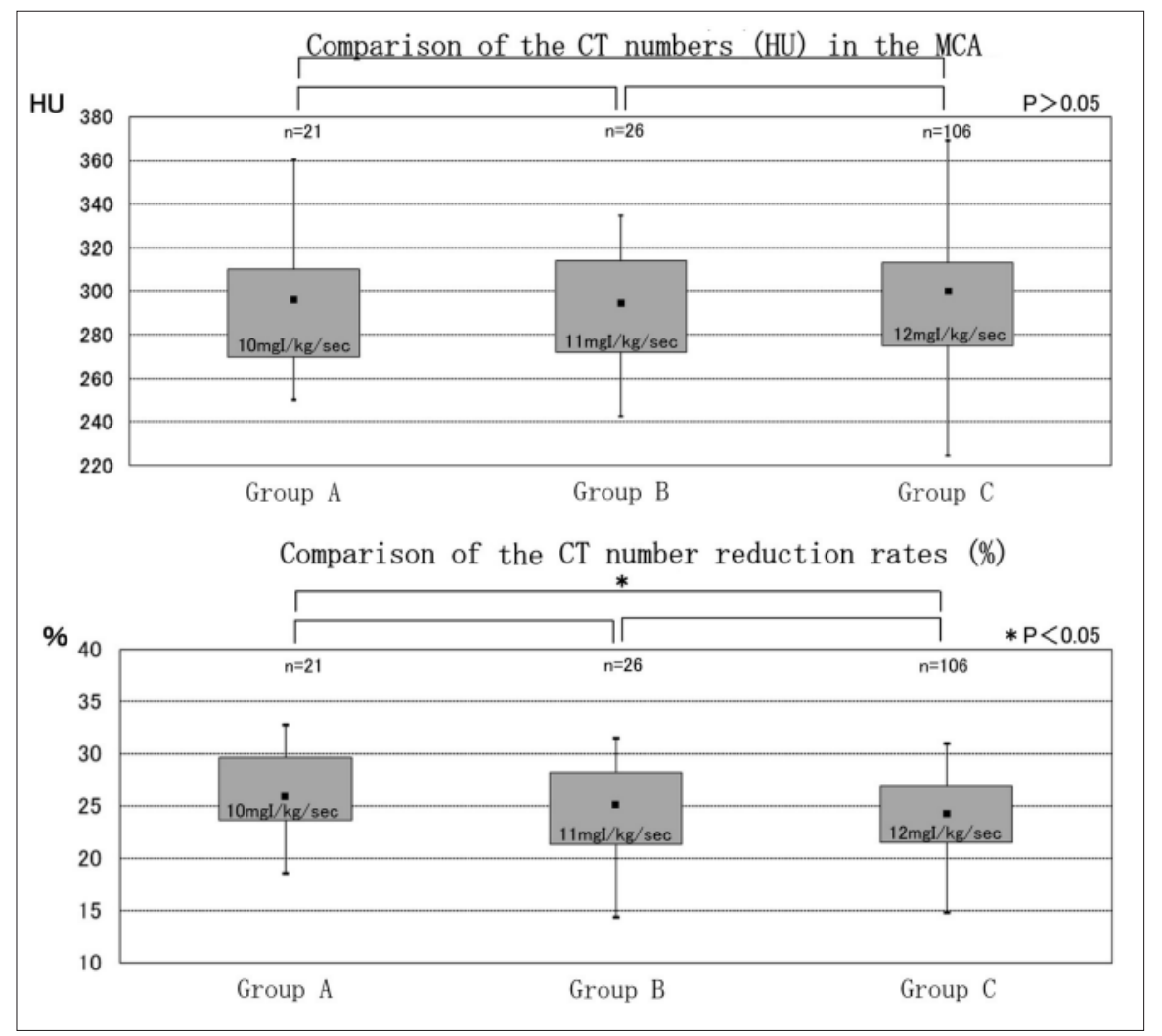

Fig. 6 Comparison of the CT numbers (HU) in the MCA and comparison of the CT number reduction rates $(\%)$ in the first groups (groups A, $\mathrm{B}$, and $\mathrm{C})$.

Table 3 Gender differences in the data sets of the first groups (groups A, B, and C)

\begin{tabular}{|c|c|c|c|c|c|c|}
\hline $\begin{array}{c}\text { group A } \\
(10 \mathrm{mgl} / \mathrm{kg} / \mathrm{sec})\end{array}$ & $\mathrm{n}$ & $\begin{array}{l}\text { body } \\
\text { weight } \\
(\mathrm{kg})\end{array}$ & $\begin{array}{c}\text { age } \\
(\mathrm{y})\end{array}$ & $\begin{array}{c}\text { CT number } \\
\text { MCA } \\
(\mathrm{HU})\end{array}$ & $\begin{array}{c}\text { CT number } \\
\text { ACA } \\
(\mathrm{HU})\end{array}$ & $\begin{array}{c}\mathrm{CT} \text { number } \\
\text { reduction rate } \\
(\%)\end{array}$ \\
\hline male & 12 & $59 \pm 10.6$ & $63.9 \pm 10.2$ & $293.3 \pm 34.2$ & $217.5 \pm 25.9$ & $25.8 \pm 3.4$ \\
\hline female & 9 & $55 \pm 7.4$ & $61.4 \pm 9.2$ & $298.3 \pm 24.6$ & $218.9 \pm 26.6$ & $26.8 \pm 4.8$ \\
\hline $\begin{array}{c}\text { group B } \\
(11 \mathrm{mgl} / \mathrm{kg} / \mathrm{sec})\end{array}$ & $\mathrm{n}$ & $\begin{array}{l}\text { body } \\
\text { weight } \\
(\mathrm{kg})\end{array}$ & $\begin{array}{c}\text { age } \\
(\mathrm{y})\end{array}$ & $\begin{array}{c}\text { CT number } \\
\text { MCA } \\
(\mathrm{HU})\end{array}$ & $\begin{array}{c}\text { CT number } \\
\text { ACA } \\
(\mathrm{HU})\end{array}$ & $\begin{array}{c}\mathrm{CT} \text { number } \\
\text { reduction rate } \\
(\%)\end{array}$ \\
\hline male & 15 & $66.4 \pm 9.4 \star \star$ & $56.5 \pm 18.5$ & $298.3 \pm 26.6$ & $223.9 \pm 23.8$ & $24.9 \pm 5.1$ \\
\hline female & 11 & $53.6 \pm 7.1$ & $60.7 \pm 14.8$ & $286.6 \pm 22.3$ & $218.2 \pm 17.5$ & $23.8 \pm 3.6$ \\
\hline \multicolumn{7}{|l|}{$\star \star \mathrm{P}<0.01$ vs female } \\
\hline $\begin{array}{c}\text { group C } \\
(12 \mathrm{mgl} / \mathrm{kg} / \mathrm{sec})\end{array}$ & $\mathrm{n}$ & $\begin{array}{l}\text { body } \\
\text { weight } \\
(\mathrm{kg})\end{array}$ & $\begin{array}{l}\text { age } \\
(\mathrm{y})\end{array}$ & $\begin{array}{c}\text { CT number } \\
\text { MCA } \\
(\mathrm{HU})\end{array}$ & $\begin{array}{c}\text { CT number } \\
\text { ACA } \\
(\mathrm{HU})\end{array}$ & $\begin{array}{c}\mathrm{CT} \text { number } \\
\text { reduction rate } \\
(\%)\end{array}$ \\
\hline male & 44 & $62.7 \pm 10.2 \star \star$ & $61.7 \pm 12.8^{\star}$ & $294.8 \pm 33.1$ & $222.6 \pm 30.3$ & $24.6 \pm 3.7$ \\
\hline female & 62 & $52.6 \pm 9.2$ & $66.4 \pm 11$ & $299.4 \pm 27.2$ & $229.1 \pm 26.3$ & $23.6 \pm 3.8$ \\
\hline
\end{tabular}

$\star \star \mathrm{P}<0.01,{ }^{\star} \mathrm{P}<0.05$ vs female 
Table 4 Mean and standard deviation of all data sets of the second groups (groups B' and C) in which the same protocols were used

\begin{tabular}{ccccccccc}
\hline \hline group & $\begin{array}{c}\text { protocol } \\
(\mathrm{mgl} / \mathrm{kg} / \mathrm{sec})\end{array}$ & $\mathrm{n}$ & $\begin{array}{c}\text { body } \\
\text { weight } \\
(\mathrm{kg})\end{array}$ & $\begin{array}{c}\text { age } \\
(\mathrm{y})\end{array}$ & $\begin{array}{c}\text { trigger } \\
\text { time } \\
(\mathrm{sec})\end{array}$ & $\begin{array}{c}\text { CT number } \\
\mathrm{MCA} \\
(\mathrm{HU})\end{array}$ & $\begin{array}{c}\text { CT number } \\
\text { ACA } \\
(\mathrm{HU})\end{array}$ & $\begin{array}{c}\text { CT number } \\
\text { reduction rate } \\
(\%)\end{array}$ \\
\hline B' & 12 & 17 & $58.9 \pm 7.8$ & $64.4 \pm 13.4$ & $19.5 \pm 2.8$ & $325.7 \pm 35.8 \star \star$ & $246.4 \pm 28.1 \star \star$ & $24.3 \pm 3.7$ \\
C & 12 & 106 & $56.8 \pm 10.8$ & $64.4 \pm 12$ & $19.4 \pm 2.9$ & $297.5 \pm 29.7$ & $226.4 \pm 28.1$ & $23.9 \pm 3.8$ \\
\hline
\end{tabular}

$\star \star \mathrm{P}<0.01$ VS group $\mathrm{C}$ Student's t-test

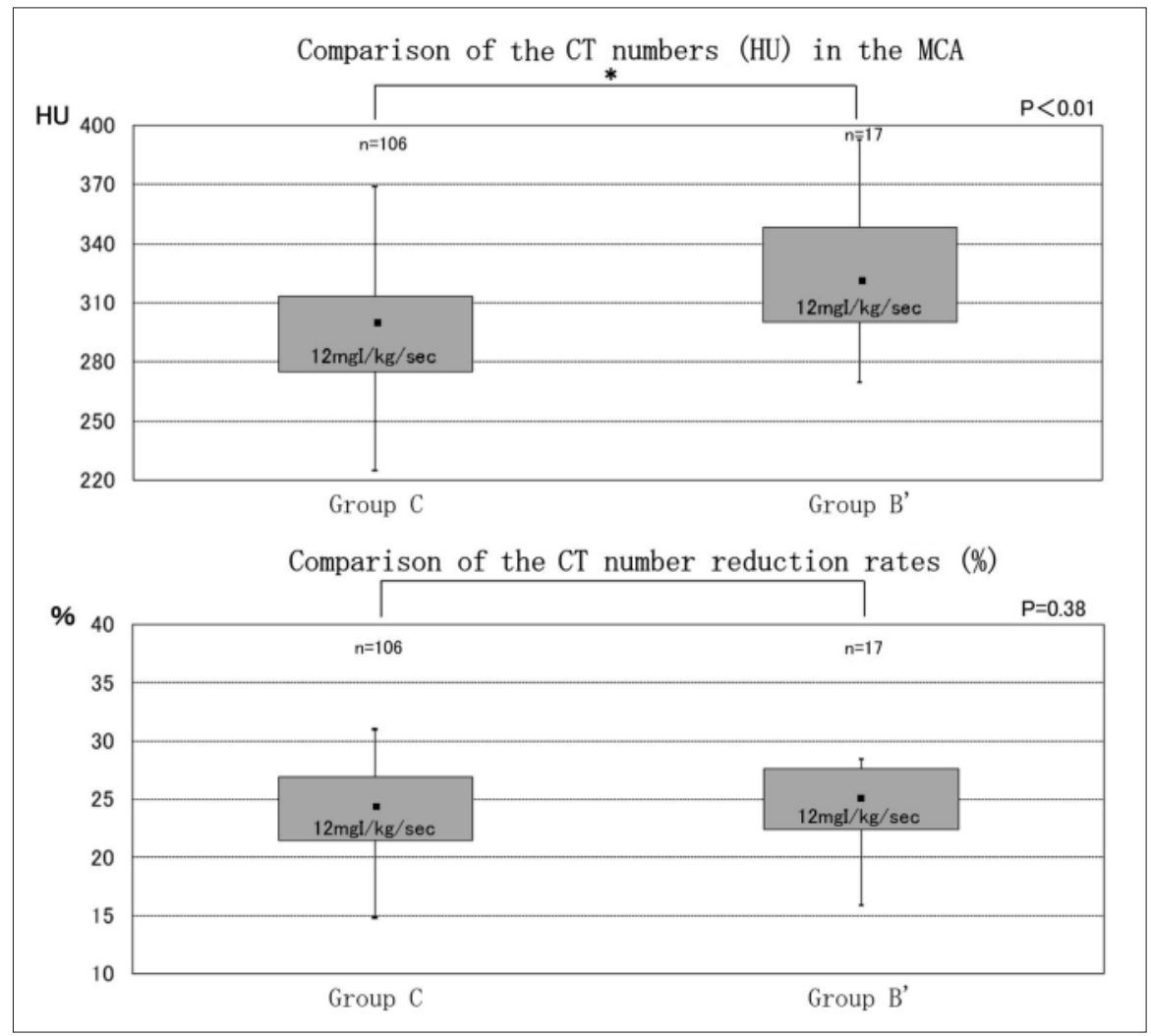

Fig. 7 Comparison of the CT numbers $(\mathrm{HU})$ in the MCA and comparison of the CT number reduction rates $(\%)$ in the second groups (groups $\mathrm{B}^{\prime}$ and $\mathrm{C}$ ).

Table 5 Mean and standard deviation of the scan time and the amount of contrast medium for each group

\begin{tabular}{ccccc}
\hline \hline group & protocol $(\mathrm{mgl} / \mathrm{kg} / \mathrm{sec})$ & $\mathrm{n}$ & scan time $(\mathrm{sec})$ & iodine volume $350 \mathrm{mgl} / \mathrm{mL}(\mathrm{mL})$ \\
\hline A & 10 & 21 & $25.1 \pm 2$ & $65.8 \pm 14.2$ \\
B & 11 & 26 & $14.1 \pm 0.7$ & $46.5 \pm 8.7$ \\
$B^{\prime}$ & 12 & 17 & $14.2 \pm 0.9$ & $51.9 \pm 9.8$ \\
C & 12 & 106 & $8.3 \pm 0.8$ & $35.1 \pm 6.7$ \\
\hline
\end{tabular}

\section{2-4一群と二群における撮像時間と造影剂使用量の 関係}

Table 5に各グループの撮像時間および造影剤使用量 の平均值と標準偏差を表記した。一群となる $\mathrm{A} ， \mathrm{~B}$ お よびCの造影剂使用量 $(\mathrm{mL}$ ：ヨード濃度 $350 \mathrm{mgI} / \mathrm{mL})$ を 比較すると，グループAは65.8 $\pm 14.2 \mathrm{~mL}(23 \pm 4.9 \mathrm{gI})$, グループ $\mathrm{B}$ は $46.5 \pm 8.7 \mathrm{~mL}(16.3 \pm 3.1 \mathrm{gI})$, グループCは $35.1 \pm 6.7 \mathrm{~mL}(12.3 \pm 2.4 \mathrm{gI})$ であった.MCAのCT值と造
影剤使用量の関係をFig. 8に示す。また, 撮像時間と 注入時間および注入時間と体重毎ヨード量の関係を Fig. 9に示す。ただし，撮像時間は8.3 $00.8 〜 25.1 \pm 2$ 秒 の範囲である。なお，二群となる $\mathrm{B}^{\prime} と \mathrm{C}$ を比較すると

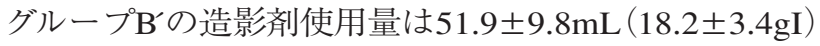
となり，同一プロトコルでは撮像時間の延長により ヨード使用量が増加した。 


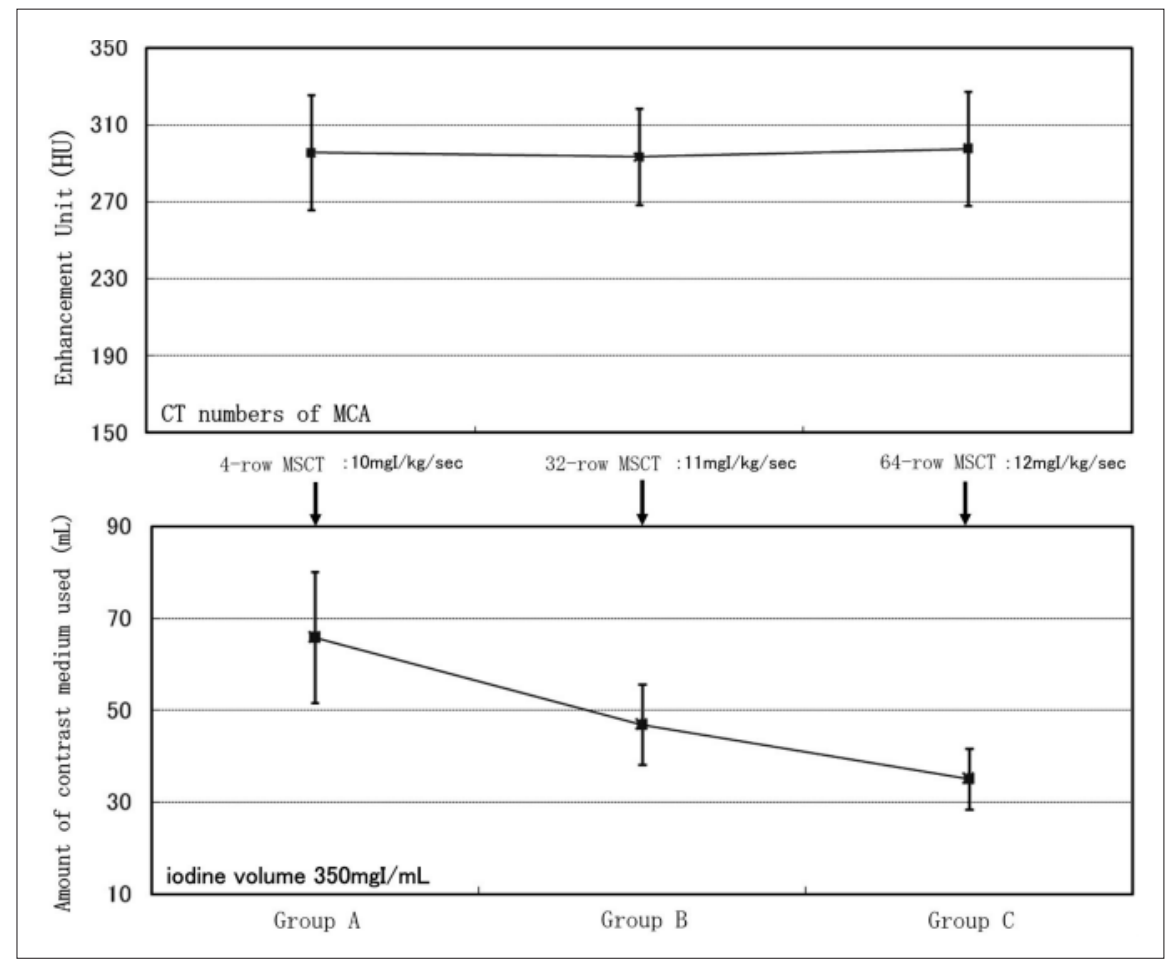

Fig. 8 Comparison of the CT numbers $(\mathrm{HU})$ in the MCA and comparison of the amount of contrast medium in the first groups (groups A, B, and C).

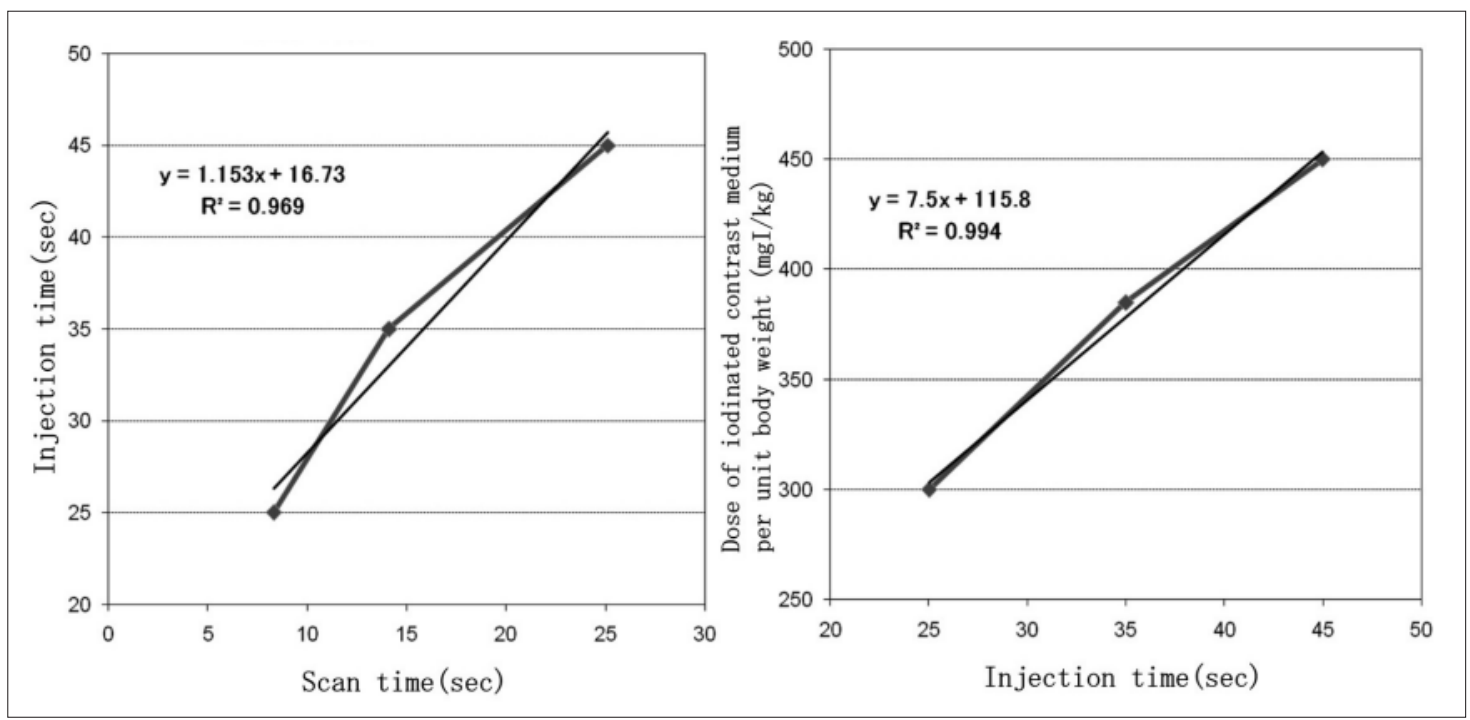

Fig. 9 Relationship between scan time and injection time and relationship between injection time and dose of iodinated contrast medium per unit body weight $(\mathrm{mgl} / \mathrm{kg})$.

\section{3. 考 察}

撮像時間に合わせ造影剂使用量を最適化するために は目標とする最大CT值を基準点とし，撮像時間を基 に造影剤使用量を決定する必要がある。ただし，目標 とする最大CT值は検査目的および施設ごとに基準が あると考える。しかし，TDCの基準点が決定されれ ば，撮像時間が違い造影法を変化させた一群(グルー プA，BおよびC)の結果より撮像時間に合わせ体重・ 時間毎ヨード量を補正することで最大CT值のバラツ
キを小さくすることが可能となる。このことは，撮像 時間が違い同一の造影法を施行した二群 (グループB' とC)の造影効果を比較することから検証することがで きる。それは，2-3よりグループCに対し撮像時間が長 いグループBにおおいてCT值低下率は影響を受けるこ となくMCAとACAのCT值が有意に上昇したことであ る(Fig. 7).つまり, 撮像時間の延長によって最大CT 值を上昇させたことになり，同一の造影法を用いた場 合, MSCTの検出器列によって撮像時間が大きく変化 
してしまうと高い再現性は得られないのである。この 原因は，再循環分 ${ }^{8,9)}$ の造影効果が加算され最大CT值 が高くなるためと考えられる. Fig. 5よりヨード濃度 が上昇した再循環血流に注入が持続されれば，ヨード が加算され緩やかに上昇する。この時間は造影剂の検 出時間 +10 秒程度であるが，生体においても同様と考 えられる。故に，体重・時間毎ヨード量を一定にした 場合，撮像時間が変化すると同様の造影効果が得られ ないことから，最大CT值を一定にする因子として， 撮像時間に対応させ体重・時間毎ヨード量を可変させ ることが妥当であり，再循環分の造影効果を補正でき ると考える。

トリガータイミングに違いが認められた原因として は，注入速度の違いによる影響と推測される。これ は, Fig. 4より撮像時間が短くなると, 短い時間に高 いピークを得ようとするため注入速度が早くなる。し たがって，単位時間当たりのヨード使用量が増加し， TDCの立ち上がりの傾き [単位時間当たり上昇CT值 $(\mathrm{HU} / \mathrm{sec})]^{9)}$ が変化する。このことから，TDCの立ち 上がりの傾きが違うとCT值の上昇速度も変化するた め夕イミングを捉えるトリガー時間に差が生じたと考 える。

造影剤使用量について，2-4より撮像時間が違い造
影法を変化させた一群のヨード使用量を比較すると (Fig. 8)，TDCの最大CT值を揃える造影法によって撮 像時間の短縮は，ある程度の水準まで低減が可能にな る。また，Fig. 9より撮像時間と注入時間 $\left(\mathrm{R}^{2}=0.969\right)$ および注入時間と体重毎ヨード量 $\left(\mathrm{R}^{2}=0.994\right)$ とも強い 相関を認めたことから，回帰式を用いて撮像時間から 最適な造影剤注入時間および体重毎ヨード量を決定で きると考える。例えば, $60 \mathrm{~kg}$ の被検者で撮像時間を 10 秒, ヨード濃度 $350 \mathrm{mgI} / \mathrm{mL}$ の造影剤を使用する場合, 検査時間は $1.153 \times 10+16.73=28.3(\mathrm{sec})$, 体重毎ヨード 量は7.5×28.26+115.8=327.3 ( $\mathrm{mgI} / \mathrm{kg})$ と計算される. そして，造影剂の注入速度は $(327.3 \times 60 / 350) / 28.3=2.0$ $(\mathrm{mL} / \mathrm{sec})$ となる。

\section{結 語}

今回の検討から，目標である最大CT值の変動を低 く抑え再現性を確保することが可能になり，撮像時間 を基準に体重・時間毎ヨード量 $(\mathrm{mgI} / \mathrm{kg} / \mathrm{sec})$ を可変さ せる投与法は，3D-CTA検査における造影法を最適化 する方法として有用と考える。

なお，本論文の要旨は日本放射線技術学会第63回総 会学術大会 (2007年, 横浜)において発表した。

\section{参考文献}

1) 八町 淳, 輪湖 正. 螺旋走査型CTに打ける最適造影検査 方法の検討。日獨医報 $1995 ； 40(2) ： 109-124$.

2) 山口 功, 石田智一, 木戸屋栄次, 他. Time-density Curve の形成過程分析から考察する撮影夕イミングの決定方法 日放技学誌 $2005 ; 61(2): 260-267$.

3）市川智章. CT造影理論. 東京 : 医学書院, 2004.

4) Bae KT, Heiken JP, Brink JA. Aortic and hepatic peak enhancement at CT: effect of contrast medium injection ratepharmacokinetic analysis and experimental porcine model. Radiology 1998; 206 (2): 455-464.

5) Ono S, Akaizawa T, Gotou R, et al. Analysis of time-density curves of contrast media for improvement of chest dynamic incremental CT. J Comput Assist Tomogr 1999; 23 (5): 753 757.
6) Awai K, Hatcho A, Nakayama Y, et al. Simulation of aortic peak enhancement on MDCT using a contrast material flow phantom: feasibility study. AJR Am J Roentgenol 2006; 186 (2): 379-385.

7) 寺沢和晶, 八町 淳. 頭部掞よび頭頸部3DCTAにおける造 影検査法の検討. 日放技学誌 2004 ；60(3)：423-428.

8) 山口 功, 林 弘之, 鈴木正行, 他. 薬物動態解析を用い た大動脈における造影剂濃度变化の推測：MDCTを使用し た急速静注下造影検査. 日放技学誌 2007 ；63(6)：621627.

9) 八町 淳. CT造影理論一ヨード造影剤の濃度, 容量および 注入速度がTDCに与える影響一。映像情報 (M) 2007；39 (6) : 604-609. 


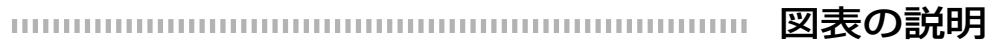

Fig. 1 TDCファントムおよびそのセッティング

Fig. 2 リアルプレップとインジェクタ同期による3D-CTA検査の流れ

Fig. 3 撮像範囲 (a) および評価部位 (b)

Fig. 4 体重·時間毎ヨード量 $(\mathrm{mgI} / \mathrm{kg} / \mathrm{sec})$ を変化させた場合における注入時間と最大CT值の関係

Fig. 5 再循環が加算されたTDC (注入時間と最大CT值の関係)

Fig. 6 一群 (グループA，B抢よびC)に扔けるMCA (HU) とCT值低下率 $(\%)$ の関係

Fig. 7 二群 (グループB`とC)におけるMCA (HU) とCT值低下率 $(\%)$ の関係

Fig. 8 一群(グループA, B およびC)に打ける MCA (HU) と造影剤使用量の関係

Fig. 9 撮像時間と注入時間および注入時間と体重毎ヨード量 $(\mathrm{mgI} / \mathrm{kg})$ の関係

Table 1 各グループの被検者数と造影プロトコル

*撮像時間 グループA：25秒程度，グループ $\mathrm{B}$ 抢よび $\mathrm{B}^{\prime}: 15$ 秒程度，グループC $: 8$ 秒程度

*CT装置 グループA：Asteion 4 列MSCT，グループBおよびB'：Aquilion 32列MSCT，グループC：Aquilion 64列MSCT

*造影剂注入時間=検査時間 -15 秒=(トリガー時間+音声・寝台移動時間+撮像時間 $)-15$ 秒

Table 2 一群(グループA，B抢よびC)に扔ける被検者データの平均值と標準偏差

Table 3 一群(グループA, B 抢よびC)に扔ける被検者デー夕の性差

Table 4 プロトコルを同一にした二群 (グループB'とC)に抢ける被検者データの平均值と標準偏差

Table 5 各グループにおける撮像時間および造影剤使用量の平均值と標準偏差 